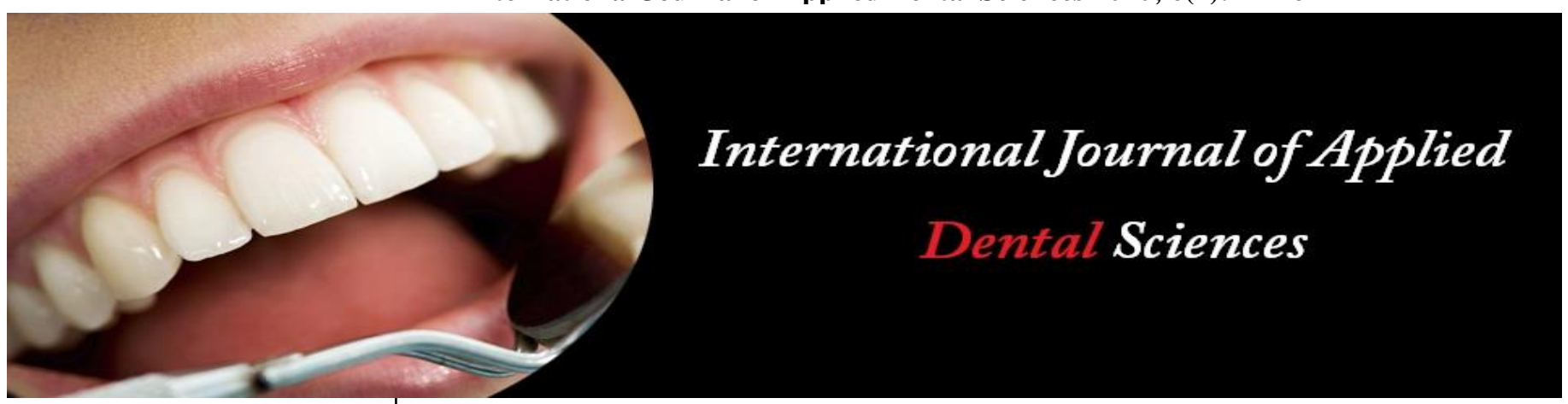

ISSN Print: 2394-7489

ISSN Online: 2394-7497

IJADS 2020; 6(4): 74-76

(C) 2020 IJADS

www.oraljournal.com

Received: 19-09-2020

Accepted: 26-10-2020

Hamza Alsharief

Restorative Department, Dental

Centre, Alnoor Specialist

Hospital, An Naseem, Mecca

24242, Saudi Arabia

Feras Aalam

Restorative Department, Dental

Centre, Alnoor Specialist

Hospital, An Naseem, Mecca

24242, Saudi Arabia

Mohammed Sannan

Restorative Department, Denta

Centre, Alnoor Specialist

Hospital, An Naseem, Mecca

24242, Saudi Arabia

Mohammed Nabeel

Restorative Department, Dental

Centre, Alnoor Specialist

Hospital, An Naseem, Mecca

24242, Saudi Arabia

Corresponding Author:

Hamza Alsharief

Restorative Department, Dental

Centre, Alnoor Specialist

Hospital, An Naseem, Mecca

24242, Saudi Arabia

\section{Periorbital emphysema after accidental root canal perforation: Case report}

\author{
Hamza Alsharief, Feras Aalam, Mohammed Sannan and Mohammed \\ Nabeel
}

DOI: $\underline{\text { https://doi.org/10.22271/oral.2020.v6.i4b.1048 }}$

\section{Abstract}

Introduction: Subcutaneous emphysema is a rare dental complication of severe medical complication. Proper case diagnosis and management rely only upon a published case report. The dentist could easily misdiagnosis such cases. In this case report, we presented precise case management from diagnosis to prevention.

Objective: provided clear guidelines regarding diagnosis, management and prevention.

Methodology: We presented a report of an interesting clinical case of periorbital emphysema develops immediately after using airway syringe to dry root canal.

Keywords: emphysema, stropko irrigator, triple way syringe, air-driven handpiece

\section{Introduction}

Cervicofacial subcutaneous emphysema defined as the abnormal introduction of air or gas in the subcutaneous tissues of the head and neck ${ }^{[1]}$. The first instance was reported by Turnbull in 1900 when a musician blew a bugle immediately after tooth extraction ${ }^{[2,3]}$. Orbital emphysema occurs when air collects in the periorbital and intraorbital spaces ${ }^{[4]}$. The widespread using air-driven handpiece and air-water syringe have increased the risk of subcutaneous emphysema SCE ${ }^{[5]}$.

We report here, a case of cervicofacial subcutaneous emphysema (SCE) occurring during endodontic treatment. The patient developed swelling of a left eye using a traditional air-water syringe. We describe its aetiology, management, and prevention during nonsurgical endodontic treatment.

\section{Case report:}

A 58-years-old woman, healthy patient (ASA1), presented at the Endodontic department to complete previously initiated root canal treatment of upper left first molar. The emergency treatment, pulpotomy, done at primary health care and the tooth restored with a temporary restoration. Radiographically, the tooth has apical radiolucent related to mesial root. After complete clinical and radiographical examination, the diagnosis achieved confirm and treatment plan discussed with the patient.

In the first appointment, Local anaesthesia administration with buccal infiltration, then rubber dam isolation and access modification. After working length determination and during flaring of coronal one third, they are using ProTaper universal SX ((DENTSPLY MAILLEFER)). Unfortunately, about $4 \mathrm{~mm}$ of orifice shaper tip separated in coronal one-third of Mesiobuccal canal (MB1). The dentist proceeds for cleaning and shaping distobuccal (DB) and palatal canals. Irrigation solution of sodium hypochlorite 5.25 delivered in microneedle of gauge 27 . the patient then schedules for another appointment for removal the separated file and then obturation.

In the second visit, obturation of both, DB and palatal root canals, completed. During removal of the separated file, the whole segment of the separated part of orifice shaper pushed apically. Then, the dentist decided to referrer the case to the specialist for management. 
In the third visit, the case is seen with the specialist, the under microscope. He was able to identify MB2 and prepared it to full working length. At the same time, the trying to remove the separated file from MB1, with ultrasonic from Sybron Endo. Unfortunately, perforation occurred in apical one third. In trying to improve vision in the operative field, Air water syringe ( 3 in 1 syringe) is used to dry the canal. Suddenly, the patient developed an apparent swelling of the left eye, that recognized by dental assistance. The swelling involves her upper and lower eyelid with little discomfort. Immediately, the endodontist terminated the procedure, reassuring the patient, and he asked for oral surgeon specialist consultation. Her vital signs are within normal, and the patient was calm and cooperative. The swelling has Classical character of SCE clinical presentation of crepitus palpation. Maxillofacial specialist confirms the diagnosis. An Antibiotic of Augmentin $625 \mathrm{mg}$ TID and analgesic of ibuprofen 200mg TID prescribed, and the patient kept for contact and followed up. The signs and symptoms were improved day by day till wholly resolved after five days of the accident - the treatment completed after ten days by tooth extraction as the patient not willing to complete root canal treatment.

\section{Discussion}

As by definition, the emphysema occurs by air forced or buildup into soft tissue by trauma, odontogenic infection ${ }^{[6,7]}$, high-speed air pressure handpiece and triple way syringe ${ }^{[8]}$ or chemical irrigation solutions ${ }^{[9]}$.

In literature, SCE most commonly occurs from surgical extraction of lower molars teeth, especially third molars ${ }^{[10]}$, because they have a closer root relationship with most of the head and neck spaces ${ }^{[5]}$. In rare cases, SCE happens in both surgical and nonsurgical endodontic intervention ${ }^{[5]}$. Simple restorative treatment not immune to SCE, where soft tissue either compromised ${ }^{[11]}$ or non-compromised ${ }^{[12]}$. In a scarce case report, SCE developed in the management of periimplantitis with air-powder abrasive ${ }^{[13]}$.

Although the medical complications of routine dental treatment are not expected, when they occurred in its majorities of little or no medical health issues in a healthy patient.

Subcutaneous emphysema SCE considered a severe health issue that required proper evaluation and correct diagnosis. Unrecognized or misdiagnosis SCE, can lead to severe complication sequels ${ }^{[8]}$. Complication varies from secondary infection ${ }^{[14]}$ to airway obstruction, mediastinitis, necrotizing fasciitis, optic nerve ischemia or even blindness ${ }^{[6]}$. It depends on the SCE location and severity. Angioedema that results from an allergic reaction to local anaesthesia or nonsteroidal anti-inflammatory drug has similar clinical features to SCE ${ }^{[15]}$. Sodium hypochlorite accident

A secondary infection developed must probably, due to the spreading of pathological bacterial into oft tissues space create by SCE ${ }^{[16]}$.

The potential risk of subcutaneous emphysema from dental intervention came from the use of high-speed air-driven handpiece ${ }^{[5,10,17]}$ and air blow with an air syringe to dry the cavity or root canal ${ }^{[1]}$. There is a single case reported case of subcutaneous emphysema due to irrigation solution hydrogen peroxide ${ }^{[18]}$. The link between SCE and irrigation solution may be due to, irritation to soft tissues or mechanical trauma. Fortunately, Mot risk factor for the development of SCE is preventable. Safe impact air surgical handpiece and Stropko irrigator with minimum and control air pressure is available and highly recommended when potential risk increase. In endodontic, the paper point is the safest approach to dry the root canals. The air of high pressure from any source should be used with caution in every case. And should not be directed toward the root canals or areas with mucosal damage is apparent. The mechanism of development of SCE mainly by forced air under pressure into periodontal tissues through perforation site or large apical root foramen. The air passes underneath the frontal periosteal to accumulate in Perioorbital space ${ }^{[16]}$

However, the SCE has terrible health experience for both patient and medical team. This experience may affect the patient to decide on the treatment provided. In our case, the patient decided to extract the tooth rather than complete the root canal procedures.

In literate, no clear guideline for the management of SCE that help practitioner for best treatment outcome ${ }^{[19]}$. The management approaches recommended varied from case to case. In our patient, Augmentin provided broad-spectrum cover against bacterial infection.

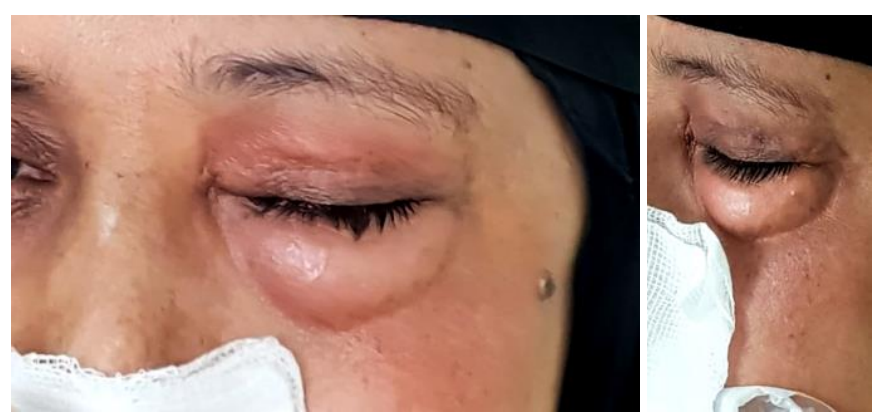

\section{References}

1. Al-Qudah A, Amin F, Hassona Y. Periorbital emphysema during endodontic retreatment of an upper central incisor: a case report. Br Dent J 2013;215(9):459-61.

2. Pynn BR, Amato D, Walker DA. Subcutaneous emphysema following dental treatment: a report of two cases and review of the literature. J Can Dent Assoc 1992;58(6):496-9.

3. Turnbull A. A Remarkable Coincidence in Dental Surgery. British Medical Journal 1900;1(2053):11311131.

4. Uyanık LO et al. Periorbital emphysema during dental treatment: a case report. Oral Surg Oral Med Oral Pathol Oral Radiol Endod 2011;112(6):e94-6.

5. Durukan $\mathrm{P}$ et al. Cervicofacial emphysema and pneumomediastinum after a high-speed air drill endodontic treatment procedure. Am J Emerg Med 2012;30(9):2095.e3-6.

6. Bali RK et al. A review of complications of odontogenic infections. Natl J Maxillofac Surg 2015;6(2):136-43.

7. Dyrhovden $\mathrm{R}$ et al. The bacterial aetiology of pleural empyema. A descriptive and comparative metagenomic study. Clin Microbiol Infect 2019;25(8):981-986.

8. Parkar A et al. Periorbital oedema and surgical emphysema, an unusual complication of a dental procedure: a case report. Cases J 2009;2:8108.

9. Singh PK. Root canal complications: 'the hypochlorite accident'. Sadj 2010;65(9):416-9.

10. Bekiroglu F, Rout PG. Surgical emphysema following dental treatment: two cases. Dent Update 1997;24(10):412-4.

11. Chang $\mathrm{CH}$, Lien WC. Palpebral emphysema following a dental procedure. Am J Emerg Med 2018;36(5):908.e1- 
908.e2.

12. Liebenberg WH, Crawford BJ. Subcutaneous, orbital, and mediastinal emphysema secondary to the use of an air-abrasive device. Quintessence Int 1997;28(1):31-8.

13. Lee S-T, Subu MG, Kwon T-G. Emphysema following air-powder abrasive treatment for peri-implantitis. Maxillofacial plastic and reconstructive surgery 2018;40(1):12-12.

14. An GK, Zats B, Kunin M. Orbital, mediastinal, and cervicofacial subcutaneous emphysema after endodontic retreatment of a mandibular premolar: a case report. $\mathbf{J}$ Endod 2014;40(6):880-3.

15. Frühauf $\mathbf{J}$ et al. Soft tissue cervicofacial emphysema after dental treatment: report of 2 cases with emphasis on the differential diagnosis of angioedema. Arch Dermatol. 2005;141(11):1437-40.

16. Mishra L et al. Iatrogenic subcutaneous emphysema of endodontic origin - case report with literature review. J Clin Diagn Res. 2014;8(1):279-81.

17. Kim Y, Kim MR, Kim SJ. Iatrogenic pneumomediastinum with extensive subcutaneous emphysema after endodontic treatment: report of 2 cases. Oral Surg Oral Med Oral Pathol Oral Radiol Endod 2010;109(2):e114-9.

18. Bhat KS. Tissue emphysema caused by hydrogen peroxide. Oral Surg Oral Med Oral Pathol 1974;38(2):304-7.

19. Pais ES. The causes of subcutaneous emphysema of relevance to dental practitioners? Evid Based Dent 2019;20(4):111-112. 